\title{
Slide Collections in Art Libraries
}

\begin{abstract}
Most slide collections in academic institutions began as small teaching collections on individual professors' desks and required little if any professional expertise to administer. As they have grown, they have become increasingly complex, but as yet there has been developed no substantial body of professional literature concerning them. The paper describes a project, currently underway, to help remedy that lack.
\end{abstract}

$\mathrm{T}$ RADITIONALly, slide collections in most United States colleges and universities have been initiated by art history faculty to illustrate lectures. These collections were often small, consisting of several boxes of slides relating only to a few specialized subject areas. Because of the size of the collections and the limited demands of the faculty, it was generally assumed that these incipient slide "libraries" required minimal supervision and attention to basic library principles such as cataloging and classification. Generally, part-time students in the department were employed to perform clerical tasks and finally when the collection expanded to burdensome proportions, a full-time person, usually with art history background but almost never with library training, was hired. Needless to say, there were exceptions to this, and in some instances the slide facilities along with a photograph or picture collection were placed under the care of the art librarian. This administrative arrangement was unfortunately less frequently utilized. Although many of the part-time and clerical employees undoubtedly were conscientious, they could be expected to have at best only vague and instinctive notions of facets of li-

Mrs. Irvine is Assistant Fine Arts Librarian and Supervisor of the Photograph and Slide Collection, Fine Arts Library, Indiana University. brary expertise such as classification, cataloging, and circulation which would ultimately be necessary when a collection became large and began to be used by more than a few art historians.

Non-book materials have until recently suffered from professional neglect. More often than not, such collections as slides, photographs, architectural drawings, and maps were begun in a non-library situation by people who had begun gathering materials in a haphazard manner. Almost without exception, such individuals would have no basic library orientation, and it simply did not occur to them to apply techniques which might solve major problems of retrieval which would develop with the expansion of the collection. In the case of slide collections, some actually reached the 100,000 mark before the users recognized and considered the problems engendered by the lack of standardized organizational and management principles such as those used with book materials. At this point, however, even an exhaustive literature search of both library and art historical journals would shed little light on the multifarious and often exotic problems facing the inquirer. The more ambitious slide supervisor would then often turn to the only other source of information by corresponding with the supervisor of one or more of the few major collections in the country who would be able to fur- 
nish guidelines and assistance on specific problems. Individuals such as Miss Helen Chillman of Yale University, Miss Eleanor Collins of the University of Michigan, Mrs. Margaret P. Nolan of the Metropolitan Museum of Art Slide Library, and Miss Phyllis Reinhardt (the author of one of the few enlightening articles on the subject) of Smith College will perhaps testify to the fact that hardly a week goes by without an inquiry regarding slide collection problems. The generosity and patience of these individuals was and is beyond the call of duty; it is clear, however, that consultation by correspondence is not the answer to bringing about the solution for the overwhelming problems facing many of the mushrooming slide collections in the country.

Because of this lack of published information, a comprehensive study and survey of the history of the problem, the present status of slide collections, practical matters (such as equipment and photographic processing), and more formal library considerations (such as use of classification, source files, and authority files) was begun in 1968. The ultimate objective is to produce a comparative study so that slide librarians and curators might have a choice of various systems and procedures currently in practice, that they might have some background knowledge, and finally, that they might have a sense of community with others facing problems similar to theirs. The proposal of an "ideal" system is not the aim of the study, since most users of such a study will be working from already existing collections which have probably grown to such proportions that a complete revision would not be feasible.

The first step in the study was to conduct a thorough literature search of Art Index, Bibliography of Library Economy, Education Index, Library Literature, and the general periodical indexes. This search confirmed the need for a study of both practical and theoretical aspects of slide collecting. The available literature contains no substantive research and tends to be either too narrowly involved with a single aspect of one slide collection or too general in scope. It became clear that a comparative study might have some merit and that a manual of a practical nature as well as a brief history might be useful for someone attempting to deal with a large collection which had grown with little direction over a period of years.

In August 1968 an eight-page questionnaire was sent to over one hundred colleges, universities, and museums. Before the questionnaire could be mailed, however, one of the most serious problems facing this project had to be overcome: the compilation of a mailing list. The American Art Directory, the American Library Directory, and the Directory of Special Libraries and Informations Centers were consulted to identify collections. Many institutions, however, were added to the list merely because of personal knowledge and not because they appeared in any of the sources. Lack of such basic information is indicative of the need for definitive and consolidating research in this field.

The content of the questionnaire is fairly broad; it is intended to serve as a basis for a study but not as the study itself. The major categories surveyed are the history of collections; the type of classification system presently used; general operational procedures regarding the purchase and production of slides; the use of library techniques such as a shelflist, authority files, and library tools such as the Anglo-American Cataloging Rules; equipment; and a final section on the educational background of the staff. The broad scope was believed to be useful in a variety of ways. The historical section is intended to bring some perspective of the present condition of collections and the remaining six categories are designed to provide enough data about specific aspects of collections 
throughout the country so that a comparative manual may be written. It is hoped that if individuals working with these collections have a readily available source of information, they will be in a better position to examine and improve their collections on the basis of past experience rather than trial and error. Moreover, a directory of participating institutions will more than likely be included at the end of the projected manual so that supplementary correspondence regarding problems discussed in the manual may ensue. This type of list will also provide slide librarians of all backgrounds with a list of institutions which have collections worthy of study and possible emulation.

Lest an entirely dismal picture is left of the present state of slide collections, perhaps it should be noted that there are some very promising trends in the field. One of the most positive of these was the inclusion of an entire session at the College Art Association's annual meeting (January 1969) devoted to slides and photographs. Dr. Marvin Eisenberg, art history chairman at the University of Michigan and president of the College Art Association, asked the slide librarian in his department, Miss Eleanor Collins, to preside at this special session. Not only does this session indicate that art historians are beginning to recognize that a problem exists in an area upon which they are heavily dependent in their work, but also that slide librarians and curators will be given an opportunity to meet and discuss with their colleagues some of their common problems.

In addition, there is a trend in art departments to consider a basic training in the problems of slide collections as part of a graduate student's career. A noncredit course is now offered by Miss Collins at the University of Michigan to prepare potential faculty members for what they will face in slide collections and also, perhaps, to encourage some to con- sider it as a possible career. In a required introduction to graduate study for art history students at Indiana University, lectures were given by the supervisor of slides and photographs to introduce students to the various aspects of slide collecting-both personal and departmental. In all probability there are other similar courses.

The organization and development of a Slide Librarians and Curators Association in California is indicative of the trend toward more communication in this field on a more formal level between supervisors of these collections. This group has been collecting and circulating to its members information on various aspects of slide libraries.

Another trend in this area is an increase in published literature. Examples of this, in addition to the projected comparative manual, are the Metropolitan Museum of Art's Slide Classification System, and the machine-manipulable slide classification system used and developed at the University of California at Santa Cruz, both to be published by 1969 . The extremely complicated nature of many art history slide classification systems makes such publications extremely valuable contributions to the field. In addition, the Metropolitan Museum of Art has published a list of slide sources (commercial and museum) which is available there free.

All of these recent trends tend to underscore the fact that slide collections are finally coming of age in this era of materials explosion. In actuality, many of their problems are shared by all areas of library science, and it is comforting to know that a connection is being established. Any questions regarding the projected manual would be gladly entertained by the present writer. Also, if any reader of this article knows of a collection which should have been included in the survey but did not receive a questionnaire, such information would be greatly appreciated. 